\title{
Age Which Participant Stopped Smoking
}

National Cancer Institute

\section{Source}

National Cancer Institute. Age Which Participant Stopped Smoking. NCI Thesaurus. Code C156832.

The chronological age at which an individual stopped smoking. 